\title{
Long and Short Run Relationship Between Agricultural and Industrial Sectors' Growth in Ethiopia Economy: Application of Co-Integration and Error Correction Model
}

\author{
Fisseha Seyoum \\ Haramaya university, College of Agricultural and Environment Sciences, Department Agricultural Economics \\ and Agribusiness, P. O. Box 138; Dire Dawa, Ethiopia
}

\begin{abstract}
The objective of this paper was to examine the long run and short run impact of agricultural sector on the industrial sector and to determine the direction of causality in Ethiopia economy using annual time series data ranging from 1991-2015 obtained from the World Development Indicators (WDI) database. The time of analysis related was to the adoption of agricultural led industrialization (ADLI) strategy to bring food security, poverty reduction, and rapid economic growth objectives in country. The result of the Johansen Co-integration test showed that data were integrated of ordered one in both trace, and max-trace statistical tests showed that there was strong long run equilibrium relationship between agricultural and industrial sectors outputs. The Johansen error correction model (ECM) indicated that agricultural series output has long run significant and positive impact on industrial sector series output but not vice versa. In the long run, increase in agricultural sector's by one percent, being other factors held constant, the marginal industrial sector output increase by 3.39\% due to multiplier effect. Granger pair wise causality test revealed that there is unidirectional causality from industry to agriculture sector. In the long run, growth comes from agriculture to industry and in the short run; agricultural growth is caused by industrial growth. Therefore, the adoption of ADLI strategy should be strengthened the sectors forward and backward linkages to bring balance, and rapid sectorial growth to support the entire economic growth in the country.
\end{abstract}

Keywords: Ethiopia, Industry, Integration, Co-Integration, VECM, ADLI.

DOI: $10.7176 / \mathrm{JPID} / 59-02$

Publication date: February $28^{\text {th }} 2021$

\section{INTRODUCTION}

In Ethiopia, agriculture is the most important and leading sector for its economic growth. The report by Ministry of Finance and Economic Development (MoFED, 2014), showed Ethiopian agriculture is the source employment for more than $85 \%$ of its population as livelihood, $40 \%$ of national GDP, $90 \%$ of exports and provides basic needs to more than $90 \%$ of the rural poor.

In Ethiopian economic history, agriculture is the most dominant sector to realize economic growth, food security, poverty reduction and foreign earnings. However, the sector's is operated by smallholder subsistent farmers that depend on traditional technologies and has low institutional support to lead the industrial sector development and could not able to realize the long standing national economic growth and development objectives of the country.

According to Ethiopian ADLI growth document 2007, the Ethiopian economic growth genesis from agriculture and motivates the growth of other sectors particularly the industrial sector. This growth theory was formulated from the experience of the East Asian developing countries agricultural-industrial growth model. In Ethiopian economy, to improve smallholder, subsistence, low and declining in per capita agriculture productivity government has been taking different action including promotion of input and productivity enhancing technological packages through specialized extension agents.

In Ethiopian's after the adoption of ADLI strategy, the economy has showed significant improvement registering double digit growth for a more than a decade best strategy to bring rapid, broad based economic growth that reduced absolute poverty of the country population from more than $50 \%$ to $30 \%$. However, because of environmental degrdation, use of traditional technology, food insecure; the Ethiopian agriculture sector and the adopted ADLI growth strategy's sustainability has many challenges.

According to Alston and Pardey (2014), 95\% small holder farmers in Ethiopian agriculture is vulnerable to climate change and drought because they have fragmented land on average less than 0.2 hectare per household in high land areas where there is most crop production takes place, broad population with high growth rate $10^{\text {th }}$ in the world and second in Africa. As in Ethiopia 90\%, smallholder farmers are subsistence farmers produce hand to mouth for their consumption that cannot produce surplus for market or industry, so it can't lay foundation for industrial growth condition including capital formation. This shows that there is different view on Ethiopian agricultural led industrialization strategy.

Historically, the effort of industrializing the Ethiopian economy was initiated in 1950s that was focused on generous tax incentives including high level of tariff protection and provision of credit by Ethiopia banks on 
favorable terms to encourage inflow of foreign capital into the sector. However, since most of these foreign owned enterprises depended on import raw materials and had lack of forward and backward linkage with the local economy, the effort was not succeeded (UNIDO, 2000).

During 1970s, the Derg-regime initiated state owned large-scale, modern and capital intensive manufacturing industrial project in Ethiopia. However, the strategy had worsened the industry's dependence on imported technology and handicapped the development of a domestic manufacturing capability of the country. New largescale capital-intensive projects that had been taken higher investment funds allocated to the industry sector. Such projects were costly in terms of foreign exchange, both in the short-term, as virtually all the machinery has to be imported and over the long-term owing to continued imports of spare-parts and intermediate goods and debt servicing obligation. Despite industrial orientation towards the domestic market, it draws heavily on imports for inputs. This also had backward and forward linkage between agriculture and industry. Both industry and agriculture in Ethiopia was assumed at infant stage, ADLI 1991 strategy is designed and hoped to solve forward and backward linkage between the sectors strategy to transform the economy of the country.

There was a strong debate on the Ethiopian ADLI policy and strategy. The government explain that ADLI strategy is the right policy selection since has showed registered double digit economic growth in the country. On the other side, the policies opponents argue that the ADLI strategy cannot sustainable bring economic growth; alleviate poverty and food security national objectives. The impact of adopted policy and strategy should be periodical evaluated against its objectives. There is scarcity of information related to the long run relationship or impact between agricultural and industrial sectors, the direction of causalities between the sectors in the economy. Therefore, the major objective of this study was to assess the contribution of the growth of agricultural sector to the growth of industrial sector in Ethiopia. Specifically the study was set out to examine if there exist a significant long run impact of agricultural output on the growth of industrial sector output and the direction of short run causality between agricultural sector and industrial sectors in Ethiopia.

\section{Methodology}

This section deals with the methodological issues and empirical result of the study to accomplish the objectives of the study that determine the short run and long run relationship of agricultural and industry, and the direction of the causality in Ethiopia.

\subsection{Sources of data}

This paper used annual time series data of agriculture and industry sectors from 1999 to 2015 of the Ethiopia economy using time series dataset collected from World Development Indicators (WDI) of the World Bank website. The initial time was selected based on the adoption ADLI in Ethiopia. As this study examines the short run and long run agriculture and industry sectors relationship, secondary data was appropriate for the study.

\subsection{Variables definitions}

Ethiopian agriculture includes cultivation of crops and livestock production as well as forestry, fishing. Agricultural output is defined as annual agricultural value output of the sector converted in to local currency after adding up all outputs and subtracting intermediate inputs. The Ethiopian industrial sector also comprises value added in the agro-processing, mining, manufacturing, construction, electricity and water. The sector annual output valued was the net output of the sector after adding up all outputs and subtracting intermediate inputs. Both sectors were calculated without making deductions for depreciation of fabricated assets or depletion and degradation of natural resources.

\subsection{Analytical Techniques}

Theoretical, a number of variables that influences industrial development is identified and analyzed with the long and short run, and the direction of impact. It was shown that industrial development is a function of agricultural output (agri), exchange rate (exe), and other factors affecting industry output. Thus, the model for this study is specified in line with the above analysis as shown below:

Indu $=($ Agri, other variables)

Given the fact that independent variables such as agriculture, exchange, interest rate and foreign direct investment determine the changes in the dependent variable industrial output, the functional relationship between the dependent and explanatory variables in linear equation is specified as shown below:

logindu $=\mathrm{b}_{\mathrm{t}}+\mathrm{b} 1$ agrit $_{\mathrm{t}}+\varepsilon \mathrm{t}$

Following the Reynold (1985) and Ajayi (1978), the data of the variables in equation (2) is transformed into logarithm form, to remove lags, which could have resulted from bureaucratic bottlenecks. This is because using the raw data as they may lead to bias resulting to violation of the ordinary least squares and vector error correction model (VECM) assumptions. As a result, the log specification becomes:

Logagrit $=\mathrm{b}_{\mathrm{t}}+\mathrm{b} 1 \operatorname{Logindu}_{\mathrm{t}}+\varepsilon_{\mathrm{t}}$ 
Where:

Log indu $=$ logarithm of industrial output

Log agri $=$ logarithm of agricultural output

$\varepsilon_{\mathrm{t}}=$ stochastic error term

$b_{0}, b_{1}=$ represent the coefficients to the direction of relationship between agriculture and industry in Ethiopia, the research was focused only on the relationship between agriculture and industry sectors.

\subsection{Estimation Technique}

\subsubsection{Staionarity Test}

The first step to estimate the specified model is to determine the stationarity of the data used that assure the variables have stable mean and variance so that resultant regression results are meaningful. Otherwise, if nonstationarity variable is present and not checked, the existence of drift in the data sequence will signify that the regression outcome was spurious. There are three different methods for the determination of unit root, namely Augmented Dickey-Fuller (ADF) (1979), Phillips-Perron (PP) (1988), and Kwiatkowski, Phillips, Schmidt and Shin (KPSS) (1992) unit root tests. Each method of unit root has three models to be used such as intercept only, intercept and slope, and no intercept and slope models. In this paper, ADF unit root techniques was used to check whether or not the variables used in the analysis are stationary or not and in turn determine the model for analysis.

Augmented Dickey-Fuller (ADF) (1976), and Dickey and Fuller (1979, 1981) developed a method for testing the stationarity of a time series variable by directly testing the null hypothesis of the unit root (non-stationarity). The original Dickey-Fuller (DF) test is based on a simple Autoregressive of order one, AR (1) process with a white-noise disturbance. However, because of the DF test regression does not include values of variables beyond one lag, the error terms may be serially correlated; results based on such tests may be biased and are not valid (Gujarati, 2004). The ADF test avoids autocorrelation problem because it corrects for serial correlation by adding lagged-difference terms (Greene, 2006). The followings the three ADF unit root models for indu variable:

$\Delta i n d u=(\mathrm{P}-1) i n d u_{t-1}+\sum_{J=1}^{k} \theta_{j} \Delta i n d u_{t-1}+\varepsilon$

$\Delta i n d u=(\mathrm{P}-1) i n d u_{t-1}+\sum_{J=1}^{k} \theta_{j} \Delta i n d u_{t-1}+\alpha+\varepsilon$

$\Delta i n d u=(\mathrm{P}-1) i n d u_{t-1}+\sum_{J=1}^{k} \theta_{j} \Delta i n d u_{t-1}+\alpha+\beta_{t}+\varepsilon$

where $\Delta$ is the difference operator, $k$ is the auto-regressive lag length, $J$ is the number of observations in the sample, $\varepsilon$ is assumed to be a Gaussian white noise random error in the three forms, $t=1, \ldots, T$ is a term for trend and $\mathrm{P}, \alpha$ and $\beta$ are the coefficients of interest. Equation (1) represents model 1 (no constant, no trend), equation (2) model 2 (constant, no trend) and equation (3) model 3 (constant, trend).

\subsubsection{Johansen Co-Integration Test}

Before moving to co-integration test, firstly there need to determine the optimal lag-length using the most known information criteria including Akaki Information Criteria (AIC), Bayesian information criteria (BIC), and Schewerize Information Criteria (SIC). When the two or more series variables under consideration are non stationary at level and confirmed at difference in unit root test, to have the same ordered of stationarity, order of " $\mathrm{d}$ " integration. The second step is testing for co-integration among the series used. Co-integration refers to a long run equilibrium link among the series variables. The stationarity process signals an existence of long run relationship among data. This paper will employ Johansen $(1991,1995)$ co-integration procedure because this approach is performing better than other co-integration tests (Gonzalo 1994). In conducting the Johansen cointegration test estimation model:

$\Delta y_{t}=\pi y_{t-1}+\sum_{t=1}^{p-1} \Gamma_{t} \Delta y_{t-1}+u$

Where $\pi=\sum_{t=1}^{p-1} A_{t}-I \quad \Gamma=-\sum_{j=i+1}^{P} A_{t}$

$\Delta$ is the first different operators, $y_{t}$ is a vector of endogenous variables in agriculture and industry and $v_{t}$ is the error term. The matrix $\Pi$ consists of long run information between $y_{t}$ variables in the vector. We will examine the matrix rank, $r$, by testing the null hypothesis that the eigenvalues $\Pi$ is statistically different from zero. Two set of statistics purposed by Johansen and Juselius (1990) indicate the number of co integrating rank, trace statistic and maximum 
eigenvalue statistics;

$$
\begin{aligned}
& L R\left(\lambda_{\text {trace }}\right)=-T \sum_{i=r+1}^{k} \ln \left(1-\lambda_{i}\right) \\
& L R\left(\lambda_{\max }\right)=-T \ln \left(1-\lambda_{r+1)}\right)
\end{aligned}
$$

$\mathrm{T}$ is the number of observations, while $\lambda_{\mathrm{i}}$ are the estimated $p-r$ smallest eigenvalues. The null hypothesis for $\lambda$ max is $r$ of no co integrating vectors against alternative hypothesis that $r+1$ co integrating vector.

\subsubsection{Vector Error Correction Model (VECM)}

There can be a long run relationship between two series in a bivariate relationship if each series is integrated of the same order or have the same stochastic trend. If in this case, agriculture and industry are co integrated, the first difference of agriculture and industry can be modeled using a VAR, augmented by including agriculture as additional regresses. VEC with two time series variables is:

$$
\begin{aligned}
& \Delta i n d u=\beta_{10}+\beta_{11} i n d u_{-1}+\ldots+\beta_{1 p} i n d u_{-p}+\alpha_{11} \Delta i n d u_{-1}+\ldots+\alpha_{1 p} \Delta \operatorname{aag} q_{-p}+\delta_{1}\left(i n d u_{-1}-\pi a g r_{t-1}\right)+u_{1} \\
& \Delta a g r i=\beta_{20}+\beta_{21} \Delta i n d u_{t-1}+\ldots+\beta_{2 p} \Delta i n d \underline{u}_{-p}+\alpha_{2} \Delta a g q_{-1}+\ldots+\alpha_{2 p} \Delta a g q_{-p}+\delta_{2}\left(\operatorname{ind} u_{-1}-\pi a g q_{-1}\right)+u_{2}
\end{aligned}
$$

Where $\Delta$ is difference operator, indu is lnindu, and agri is lnagri, $\delta_{1}$ and $\delta 2$ are error correction coefficients, $\left(i n d u_{t-1}-\Pi a g r i_{t-1}\right)$ the error correction term, $\mathrm{u}_{1}$ and $\mathrm{u}_{2}$ is random term. In VEC model, past values of the error correction term helps to predict future values of describes how variables behave in the short run being consistent with the long run Co-integration relationship. A significant coefficient of the error correction term indicates any short term fluctuations between the independent variable and dependent variable will give rise to a stable long run relationship. To identify the long run relationship between agriculture and industry growth in Ethiopia, the model is applied.

\subsection{Granger-Causality Test}

The co-integration tests between the two sectors series using Granger causation test at least in one direction Granger (1969). So at least one coefficient of the error term should enter to equations 13 or 14 significantly and bear the correct sign, i.e. negative.

$$
\begin{aligned}
& \Delta{\text { ind } u_{t}}=\sum_{j=1}^{k} \alpha_{1 j} \Delta_{\text {Iind } u_{t-j}}+\sum_{j=1}^{k} \beta_{1 j} \Delta_{\text {agri }}{ }_{t-j}+\varepsilon_{1 t} \\
& \Delta \text { agri }_{t}=\sum_{j=1}^{k} \alpha_{1 j} \Delta{\text { ind } u_{t-j}}_{t}+\sum_{j=1}^{k} \beta_{2 j} \Delta \text { Aagri }_{t-j}+\varepsilon_{2 t}
\end{aligned}
$$

Where $\Delta$ is the first difference operators indicate that the variables are in the short run process, while $\varepsilon_{1 t}$ and $\varepsilon_{2 t}$ are white noise residuals. $F$-test is used for a restriction on the VAR parameters. It is said that if there is exist a causality, the direction between agriculture and industrial sector, the coefficient $\alpha_{12}$, k should be different from zero, that is, by rejecting the null hypothesis the null hypothesis is accepted that agriculture sector has Grangercaused industrial sector. Similarly, if $\mathrm{H} 0: \alpha_{21}, \mathrm{k}=0$; with no causality, it can be conclude that the industrial sector is Granger-caused agriculture sector.

\subsubsection{Diagnostic Checks of the Variables}

\subsubsection{Autocorrelation test}

Autocorrelation refers to existence of a relationship between error terms across observations of a time series. Error co-variances are therefore different from zero. This constitutes a violation to one of the assumptions of the classical linear model. Autocorrelation is manifested by OLS estimators which are not BLU (Best linear unbiased). In this study, auto correlation was tested using the Breusch-Godfrey (1978), serial correlation LM test. The decision rule is to accept null hypothesis of no autocorrelation among the error term across the observation of time series if the probabilities of the F-statistics of the intermediary equation are greater than 0.05 , which depict the absence of autocorrelation. On the other hand, Alternative hypothesis of autocorrelation among the error term of the observation is not rejected if the probabilities of the F-statistic of the intermediary equation are lesser than 0.05 .

\subsubsection{Residual vector normality test}

The normality test of the residuals is one of the important post-estimation diagnostic tests in empirical studies. This study uses the multivariate extension of the Jarque-Bera $(J B)$ test for residual normality, which compares the third and fourth moments of the residuals to those from the normal distribution. This test is a joint asymptotic test in which the statistic is calculated from the skewness and kurtosis of the residuals as follows.

$$
J B=\frac{T}{6}\left[S^{2}+\frac{\left(\beta_{3-3}\right)}{4}\right]
$$


Where $\mathrm{T}$ is the number of observation, $\mathrm{S}$ is the coefficient of skewness, $\beta_{3}$ is a measure of kurtosis; and the test statistic is $\chi^{2}$ distributed. The joint test is based on the null hypothesis that the residuals are normally distributed (i.e., $\mathrm{S}=0$ and $\beta_{3}=3$ ). Rejection of the null hypothesis at the standard critical values indicates non-normality of the residuals.

\section{RESULT AND DISCUSSION}

\subsection{Descriptive Statistics}

The following table, Table 1, shows the summary of agriculture and industry series output. As can be seen the mean of agriculture and industry is 14.1 billion and 3.18 billion Birr respectively over the time series period. Table 1. Descriptive Statistics of agricultural and industrial output (billion)

\begin{tabular}{llllll}
\hline Variable & Obs & Mean & Std. Dev. & Min & Max \\
\hline agri & 26 & 141 & 58.1 & 83.7 & 268 \\
indu & 26 & 31.8 & 24.7 & 9.73 & 105 \\
\hline
\end{tabular}

Source: Own Computation

From the Table, it can also show that the standard deviation of agriculture is highly larger than industry sector. This may be due to climatic variability affecting agricultural output performance.

\subsection{Econometric Analytical Test Results}

There are steps and procedures to test short run and long run relationship between agriculture and industrial sector output series including, stationary and unit root test for integration and its order, co integration if it exist and its number and short run and long run impact of the series. Post diagnostic test, which increases interpretation and reliability.

\subsection{Stationarity test}

The result of the ADF Unit Root test showed that the two variables were confirmed to be stationary only after their first differencing.

Table 2. Result of the ADF unit roots for stationarity

\begin{tabular}{lllllll}
\hline \multirow{2}{*}{ Variables } & At level & \multicolumn{2}{l}{ At first difference critical value } & & \multirow{2}{*}{ Remarks } \\
& Statistics & Statistics & $1 \%$ & $5 \%$ & $10 \%$ & \\
\hline indu & -2.878 & -4.181 & -4.38 & -3.6 & -3.24 & I(1) \\
Agri & -1.136 & -3.032 & -2.583 & -1.746 & -1.337 & I(1) \\
\hline
\end{tabular}

Source: Own Computation

The result conducted at both $1 \%$ and 5\% levels of significant is presented in Table 2 below result shows that both the series namely; industrial output (indu) and agricultural output (agri) contained unit root at level and are stationary only after first differencing, at $1 \%$ and $5 \%$ significant levels. This follows the decision rule that states when the computed absolute value of ADF exceeds the absolute critical value, the null hypothesis is rejected and concluded that the series are stationary and vice-versa.

The stationarity of both the series in the same order was thus a motivation to run for co-integration tests to find out the presence or absent of any long run relationship between the series. In view of the above, since the variables are stationary at the same order or I(1) orders, there was a need for a test for co- integration test using the Johansen (1991) co- integration technique.

4.2.2. Co-integration test analytical result

As Johansen co-integration test is lag length sensitive, optimal lag length was determined using LR, FPE, AIC, HQIC and SBIC information criteria indicated in the Table 3.

Table 3. Optimal Lag Selection Result

\begin{tabular}{|l|l|l|l|l|l|l|l|l|}
\hline Lag & LL & LR & Df & P & PEP & AIC & HQIC & SBIC \\
\hline $\mathbf{0}$ & -1166.83 & & & & $4.7 \mathrm{e}+41$ & 101.638 & 101.662 & 101.736 \\
\hline $\mathbf{1}$ & -1087.24 & $159.19^{*}$ & 4 & 0.000 & $6.6 \mathrm{e}+38^{*}$ & 95.0641 & $95.1386^{*}$ & $95.3603^{*}$ \\
\hline $\mathbf{2}$ & -1085.86 & 2.7577 & 4 & 0.000 & $8.4 \mathrm{e}+38$ & 95.292 & 95.4162 & 95.7857 \\
\hline
\end{tabular}

Source: Own Computation

Based on all the information criteria the optimal lag length was determined to be one. After determining the lag length, the next procedure is determining co integration if exist and number of co-integration using trace and max eigenvalue statistics as indicated in Table 4 below. 
Table 4. Co-integration test using trace and max statistics

\begin{tabular}{|l|l|l|l|l|l|l|}
\hline $\begin{array}{l}\text { Maximum } \\
\text { Rank }\end{array}$ & Parms & LL & $\begin{array}{l}\text { Eigen } \\
\text { value }\end{array}$ & Trace statistics & $5 \%$ critical value & $\begin{array}{l}1 \% \\
\text { value }\end{array}$ \\
\hline 0 & 6 & -1099.66 & & 27.6163 & 15.41 & 20.04 \\
\hline 1 & 9 & 1087.5365 & 0.65173 & $3.3561 * 1 * 5$ & 3.76 & 6.65 \\
\hline
\end{tabular}

\section{Source: Own Computation}

Notice: The $* 1 * 5$ indicates that this estimator has selected the number of co integrating at $1 \%$ and $5 \%$ critical value.

Table 4 above indicated the presence of (1) co-integrating equation for both trace statistics at $1 \%$ and $5 \%$ level of significance. This means Co-integration exists at those ranks where the value of the trace statistic is less than the $1 \%$ and $5 \%$ critical value. Again, the eigenvalues all lie below 1 indicates the presence of co-integration. To confirm the result done, maximum Eigenvalue test shown in the following Table 5.

Table 5. Maximum statistics co integration test results

\begin{tabular}{|l|l|l|l|l|l|l|}
\hline $\begin{array}{l}\text { Maximum } \\
\text { Rank }\end{array}$ & Parms & LL & Eigen value & Trace statistics & $\mathbf{5 \%}$ critical value & $\mathbf{1 \%}$ critical value \\
\hline $\mathbf{0}$ & 6 & -1099.66 & & 24.2602 & 14.07 & 18.63 \\
\hline $\mathbf{1}$ & 9 & 1087.5365 & 0.65173 & $3.3561 * 1 * 5$ & 3.76 & 6.65 \\
\hline $\mathbf{2}$ & 10 & 1085.8584 & 0.13577 & & & \\
\hline
\end{tabular}

Source: Own Computation.

As can be seen from Table 5 above, accepted the null hypothesis that there was a (1) co-integrating equation for maximum statistics at $1 \%$ and $5 \%$ level of significance. This confirmed the existence of co-integration exists at those ranks where the value of the trace statistic is less than the $1 \%$ and $5 \%$ critical value. The presence of cointegration between industry and agriculture indicate that there is long term equilibrium or a long run relationship between the two sectors in Ethiopia economy.

\subsubsection{Error correction model analysis}

After assurance of the presence of co-integration or long run equilibrium relationship between the two sectors the next step is to examine a Vector Error Correction Model (VECM). VECM adjusts to both short run changes in sectors, deviations from equilibrium long impact agricultural sector on industrial sector and vice versa using Johansen long run normalization restricted normalization equation and calculate the speed of adjustment of the model shock. The following Table indicates the analysis of the short run error correction model speed of adjustment.

Table 6. Short run shock from long run equilibrium adjustment

\begin{tabular}{lll}
\hline D_indu & L. cel & $-0.029(4.68)^{* *}$ \\
LD.indu & $-0.336(2.65)^{* *}$ \\
LD.agri & $-0.139(0.99)$ \\
cons & $-0.005(0.17)$ \\
\hline
\end{tabular}

Source: Own Computation

Table 9 shows short run shock from long run equilibrium adjustment in error correction mode analytical result indicate that the coefficient of the error correction term of industrial output (indu) co-integrating equation 1(L._ce1) is well behaved having possessed the expected negative sign, fractional and significant. The value of the error correction coefficient is -0.029 . This indicates that about $2.9 \%$ of the disequilibrium between the short run and long run relationship is corrected annually which is very small and it takes long time to take full adjustment once shocked the long run equilibrium . The R-squared value of 0.894 indicates that about $89.4 \%$ of the variability in industrial output in Ethiopia within the period under consideration was determined or influenced by agricultural sector output. In addition, error correction equation 2 showed that, agricultural sector output is sensitive to the shock in the short run. VECM Johansson's normalization analysis, which shows the long run impact of agricultural sector on industrial sector, is indicated in the following Table 8.

Table 7. Long run impact of agriculture on industry in Johansen normalized equation

\begin{tabular}{|l|l|l|l|}
\hline Beta & Coefficient & Standard & Probability $(<0.05)$ \\
\hline Co-integration error equation & & & \\
\hline Indu & 1 & & \\
\hline Agri & 3.3878 & 1.069 & 0.002 \\
\hline Constant & -93.69081 & & \\
\hline
\end{tabular}

Source: Own Computation.

Table 7 result shows the Johansen normalization equation analytical result in above, indicated that in the long run agricultural has posted and significant at $1 \%$ probability level. This implies that the long run agricultural sector output has long run and positive impact in on the industrial sector output equation. Marginal result indicates that 
agricultural output increased by $1 \%$, other factors being sector increase by $3.39 \%$. On the other hand there is a need to test weather is industrial sector has long run impact on agricultural sector or not. The result of Normalization equation showed in Table 8 below.

Table 8. Long run impact of industry on agriculture in Johansen normalization co-integration

\begin{tabular}{|l|l|l|l|}
\hline Beta & Coefficient & Standard & $\mathrm{P}>\mathrm{Z}$ \\
\hline Lag error correction equation 2 & & & \\
\hline agri & 1 & & \\
\hline indu & 0.295 & 1.54 & 0.124 \\
\hline Constant & -24.656 & & \\
\hline
\end{tabular}

Source: Own Computation

In the above Table 8, analytical result of the error correction model Johansen normalization restricted equation (L._ce2) indicated that industrial output (indu) was not significant on agricultural output implies that industrial sector has no long run impact on the agricultural sector.

\subsubsection{Granger causality test result}

Since it was concluded from the previous test, i.e. the co-integration test that the two series are co-integrated, then there should be Granger causation at least in one direction. So at least one coefficient of the error term should enter equations and significantly and bear the correct sign, i.e. negative. As also indicated by the Granger causality test, there is no causality between industrial output and agricultural output within the period under consideration in Ethiopia as shown in Table below.

Table 9. Granger short run causality analytical s result

\begin{tabular}{|l|l|l|l|l|}
\hline Equation & Exclude & Chi2 & Df & Prob chi2 \\
\hline Indu & Agri & 1.2062 & 2 & 0.547 \\
\hline Indu & All & 1.2062 & 2 & 0.547 \\
\hline Agri & Agri & 9.8034 & 2 & 0.007 \\
\hline Agri & All & 9.8034 & 2 & 0.007 \\
\hline
\end{tabular}

\section{Source: own computation}

Table 8 shows the result of the pair-wise Granger causality hypotheses, as shown in the null hypothesis agricultural doesn't Granger causes industry was accepted at least $10 \%$ significance level. On the other hand, the null hypothesis industry doesn't granger causes were rejected at chi2 0.007 significance level. This means uni-* directional causality runs from industry to agriculture and not viscera.

\subsection{Post-Estimation Diagnostics}

In the study, different post-estimation diagnostic tests were performed to guarantee that the residuals from the model are Gaussian that the assumptions are not violated and the estimation results and inferences are trustworthy.

\subsubsection{Lagrangian Multiplier (LM) autocorrelation test result}

The following Table, Table 12 analytical result shows weather there is serial correlation in the variables under consideration agriculture and industry outputs in Ethiopia or not.

Table 10. Lagrangian multiplier (LM) autocorrelation test result.

\begin{tabular}{|l|l|l|l|}
\hline Lag length & Chi2 & Df & Prob>chi2 \\
\hline 1 & 8.25 & 4 & 0.08 \\
\hline 2 & 1.47 & 4 & 0.83 \\
\hline
\end{tabular}

Ho: No autocorrelation at lag one

Source: Own Computation

The Table shows the null hypothesis there is no serial correlation between models variables is not rejected at probability chi $25 \%$ significance level. Thus, the study could not find any evidence of autocorrelation problem in the residuals.

\subsubsection{Residual vector normality test}

Table 11.Residuals Vector Jarque-Bera Normality Test

\begin{tabular}{|l|l|l|l|}
\hline Equation & Chi2 & Df & Prob>chi2 \\
\hline Indu & 0.537 & 2 & 0.76454 \\
\hline Agri & 0.671 & 2 & 0.71483 \\
\hline ALL & 1.208 & 4 & 0.87672 \\
\hline
\end{tabular}

Source: Own Computation

Normality is checked mainly by using the Jarque-Bera test. The result (in Table ) shows the null hypothesis that the residual vector of the model is found to be jointly normal is not rejected at $10 \%$ significant probability level which means the residual is normally distributed. 


\section{CONCLUSION AND RECOMMENDATION}

The econometric analytical result indicated that agricultural and industrial sectors output series move together. The result of the ADF stationarity unit root test indicate that both stationary of difference one and the Johnson co integration tests of maximum likelihood ratio trace and max eigenvalue statistics indicate that the variables are cointegrated of order one implies the two sectors output series in Ethiopian have long run equilibrium relationship.

Johansen normalized restricted equation error correction model indicates a $1 \%$ increase in agricultural output leads to $3.39 \%$ increase in industrial sector output being other factors held constant. This means that agricultural sector output has long run, strong and positive impact on industrial sector but no vice versa. This may be due to that fact that the industrial sector in Ethiopia is in the infant stage.

The industrial short run shock speed of adjustment from the long run equilibrium error correction term regression model coefficient was negative, fraction and significant implies that the sector is shock was responsive despite its very small $(2.9 \%)$ adjustment in the next year so that takes long time for full adjustment. The null hypothesis that says agricultural doesn't Granger causes industry was not rejected at less than $10 \%$ significance level implies that in the short run, agriculture doesn't causes industry. But the null hypothesis that says industry sector don't granger causes agriculture was rejected at $1 \%$ significance level implies that industry has short run impact on agriculture. This means in the short run industry affects agriculture and unidirectional causality running from industry sector to agriculture sector. Therefore, it can be concluded that agricultural has no short run impact on industry and industry has strong short run impact on agriculture. On the other hand, Johannes normalization equation indicates that agriculture has a strong and positive long run impact on industry and not vice versa. Implies agricultural sector output has long run on industrial sector series output. In addition, short run causality test indicated that industrial out series has short run causality on agricultural.

Therefore, policy makers should reconsider the ADLI policy strategy as the right policy and should ensure a balanced growth of both Agricultural sector and industrial sector ensuring both forward and backward linkages between the two sectors for the overall development of Ethiopian economy.

\section{REFERENCES}

Alston, J.M. and Pardey, P.G. 2014. Agriculture in the Global Economy. Journal of Economic Perspectives, Vol. 28 (1), pp. $121-146$

Dia Xinsho .2010. Economic Importance of Agriculture for Sustainable Development and Poverty Reduction: The Case Study of Ethiopia. Global Forum on Agriculture 29-30 November.

Dickey, D. and Fuller, W. 1979. Distribution of the Estimators for autoregressive time series with a unit root. Journal of the American Statistical Association, 74(3):427-431.

Dickey, D. and W. Fuller. 1976. Likelihood ratio test statistics for autoregressive time series with a unit root. Econometrical 49: 1057-1072.

Dickey, D. and W. Fuller. 1979. Distribution of the Estimators for Autoregressive Time Series with a Unit Root. Journal of American Statistics Association, 74(366): 427- 31.

Godfrey LG .1978. Testing for Higher Order Serial Correlation in Regression Equations when the Regressors Include Lagged Dependent Variables." Econometric, 46, 1303.

Granger, C.W.J. 1969. Investigating causal relations by econometric models: cross spectral methods', Econometrical, 37, 424-38

Greene, W. H. 2006. Econometric Analysis, 5th Edition Greene, Academic Internet Publishers, 2006.

Gujarati, D. 2004. Basic Econometrics. Fourth Edition. McGraw-Hill Companies.

Hye, Q.M.A.2009. Agriculture on the road to industrialization and sustainable economic Growth: An empirical investigation for Pakistan. International Journal of Agricultural Economics and Rural Development: 2: 1-6.

International Monetary Fund (IMF). Ethiopian Economic Review, 2016. Story behind the number. https://www2.deloitte.com.

Johansen, S. and Juselius, K. 1990. Maximum Likelihood Estimation and Inference on Co integration - with Application to the Demand for Money, Oxford Bulletin of Economics and Statistics, 52, 169-210.

Kwiatkowski, D., Phillips, P. C. B., Schmidt, P., and Shin, Y. 1992. Testing the null hypothesis of stationarity against the alternative of a unit root: How sure are we that economic time series have a unit root?" Journal of Econometrics, Vol.54.

Phillips, P. C. B., Schmidt, P., and Shin, Y. 1992. Testing the null hypothesis of stationarity against the alternative of a unit root: How sure are we that economic time series have a unit root? Journal of Econometrics, Vol.54, October-December (1-3), pp.

Phillips, P.C. and P. Perron. 1988. Testing for a unit root in time series regression. Biometrika, 75(2): 335-346.

Rural development policy and Strategies, 2003. Government of the federal democratic republic of Ethiopia, Addis Ababa. Ethiopia.

XINsho.2010. Policies for Agricultural Development, Poverty Reduction and Food Security OECD Head quarters, Paris. 
Koo, W. W., and Jianqiang L., 997. The Relationship between the Agricultural and Industrial sectors in Chinese Economic Development. Agricultural Economics Report No. 368. 